\title{
Yeni Zelanda tavşanında ön ekstremitelerin postnatal osteolojik gelişimi $^{*, * *}$
}

\author{
Ayhan DÜZLER ${ }^{1}$, Ahmet ÇAKIR ${ }^{2}$ \\ ${ }^{1}$ Erciyes Üniversitesi, Veteriner Fakültesi, Anatomi Anabilim Dalı, Kayseri; ${ }^{2}$ Ankara Üniversitesi, Veteriner Fakültesi, Anatomi \\ Anabilim Dalı, Ankara
}

\begin{abstract}
Özet: Bu çalışmada toplam 72 adet erkek Yeni Zelanda tavşanı'nın ön ekstremiteleri üzerinde, dogumđan 198. güne kadar osteolojik gelişim incelenmiştir. Ön ekstremite kemikleri, double staining yöntemiyle, alizarin red-S ve alcian blue kullanılarak boyanmışır. $150 \mathrm{~mm}$ 'lik kumpas yardımıyla ölçïler alınmıştır. Elde edilen boyama ve ölçüm sonuçları, fotoğraf ve grafiklerle gösterilmiş, rakamsal bulgular anlamlarıyla birlikte sunulmuştur. Rakamsal veriler ïzerinde bilgisayar ortamında Ki-kare testi, T testi ve çoklu varyans analizi uygulanmıştır. Tavşanın ön ekstremite kemiklerinde ölçülerin dönemlere, să̆ ve sol bacaklara göre istatistiksel olarak anlamlı ölçüde farklılaştığı ( $\mathrm{p}<0.09)$, ölçümlere göre să̆ bacaktaki kemiklerin sol bacaktakilerden daha büyüik olduğu tespit edilmiştir. Ön ekstremite kemiklerine ait primer ve sekonder ossifikasyon merkezleri ile ilgili ayrıntılı bilgiler edinilmiştir. Ossa carpi ve os coracoides hariç bütün ön ekstremite kemiklerinde ilk kemikleşmenin dogumdan önce başladiğı saptanmıştır. Yeni Zelanda tavşanı'nda kemik gelişim hızının ilk 15 haftada yüksek olduğu tespit edilmiştir. Sonraki 13 haftada ise gelişim hızı giderek azalmıştır. Yirmi sekiz haftalık postnatal periyodun ardından ön ekstremitede kemiksel gelişimin sona erdiği saptanmıştır. Son periyotta kıkırdak dokunun, eklem kıkırdakları, clavicula'nın iki ucı ve cartilago scapulae ile sınırlı olduğu gözlenmiştir.
\end{abstract}

Anahtar kelimeler: Kemik gelişimi, ön ekstremite, tavşan

\section{Postnatal development of the thoracic limb bones in New Zealand rabbit}

Summary: In this research, osteologic development of the bones of thoracic limb on the 72 New Zealand rabbit was investigated within a period of birth through 198 th postnatal day. The bones of thoracic limb were stained by use of alizarin red-s and alcian blue double staining method. Measuring of the bones were obtained by using a $150 \mathrm{~mm}$ calipers. The results were displayed by photography and graphics. Likewise, numerical data obtained were analysed and evaluated by use of computer with $X^{2}$ and $T$ test. The data revealed that lenght of the bones in right legs was significantly higher than that of the left legs $(p<0,09)$, thus, primary and secondary ossification centers in the bones of thoracic limbs were obtained in detail. Beginning of the ossification in all the bones of thoracic limbs except the carpal bones and os coracoides was determined before parturation. The ossification rate was found to be very high within the first 15 weeks. Later, it was shown that ossification decreased gradually for 13 weeks period. Ceasing of the ossification in the thoracic limb was determined after 28 weeks of the postnatal development. In the last period, the cartilage tissue was seen in the joint cartilages, both end of the clavicula, and cartilages of the scapula

Key words: Bone development, thoracic limb, rabbit

\section{Giriş}

Kemikler, ya kıkırdakların yerini alarak (endokondral ya da intrakartilaginöz kemikleşme) veya bağdoku'nun kemikleşmesiyle (intramembranöz kemikleşme) meydana gelirler $(6,11,18,19)$. Kemik doku embriyoda ve doğumdan sonraki dönemde (postnatal), destek dokularından bağdoku ve kıkırdak doku'nun kireçleşmesiyle meydana gelir. Gerek embriyonal ve gerekse postnatal hayatta ilk kemikleşmeler küçük sahalar (primer ossifikasyon merkezi: PM) halinde oluşur. Bu kemik odakları sonradan appositional bir kemikleşme ile genişleyip büyürler $(6,9,11)$. Ilk kemikleşmenin proksimal ve distal epifizde tekrarlanması sonucu sekonder ossifikasyon merkezleri (SM) şekillenir $(6,7,9,15,27)$.
Uzun bir kemiğin gelişiminde üç adet PM şekillenir. Bunlardan biri diyafiz ya da kemik gövdesinin gelişimi, diğer ikisi de kemiğin uçları ya da epifizlerinin gelişimi içindir. Ayrıca, uzun kemiklerin çoğu, kemik çıkıntılarını şekillendiren SM'lerine sahiptir (11).

Kemiklerdeki gelişim ve büyüme postnatal dönemde uzunca bir süre devam eder. Daha sonra, büyümeyi sağlayan epifiz plaklan hiçbir kurala bağlı olmaksızın kemikleşerek kapanır $(2,5)$.

Kemik gelişimi ve epifizeal büyüme, tavşanlar 6 aylık olduklarında sona ermekte ve epifiz plakları kapanmaktadır (14).

Tavşanda ilk 12 haftalık dönem içerisinde erişkin kemik yapısı şekillenmektedir. Kemik gelişimi 17-33.

\footnotetext{
* Aym başlıklı doktora tezinin bir bölümünün özetidir.

** Ankara Üniversitesi Veteriner Fakültesi Etik Kurul onayı alınmıştır.
} 
haftalar arasinda sona ermektedir (13). Yeni Zelanda tavşanında yapılan bir çalışmada (24), büyümenin hızının postnatal ilk 28-42. günlere kadar çok yüksek olduğu ve giderek azaldı $\breve{g}$ belirtilmektedir. Yeni Zelanda tavşanının doğum sonrası 42. günde sahip olduğu osteolojik gelişim durumu, periyot olarak 4,5 yaşındaki bir insanla eşlenebilir (15).

Tavşanın scapula'sı üzerinde " $S$ " şeklinde bir proc. hamatus, 1-1,5 cm uzunluğunda proc. suprahamatus, kanca şeklindeki proc. coracoideus yer alır $(1,5,17)$. Scapula'nın kemikleşmesi, bir primer ve iki ya da üç adet SM tarafindan sağlanır (1).

Tavşanda clavicula, bir çift kemiktir ve iskelet sistemine ait kemiklerden hiçbiriyle eklemleşmez. Kaslara gömülui olarak, musculus cleidocephalicus ile musculus cleidobrachialis arasında yer alır (17). "S" şeklinde ve 15 $20 \mathrm{~mm}$ uzunluğundadır (1).

Os coracoides, tavşanda gelişmiş ve bağımsız bir kemik şeklinde olmayıp, kalıntısı scapula üzerinde bir çıkıntı halindedir. Scapula'nın medial yüzü üzerinde ve distal'de yer alan kanca şeklindeki bu çıkıntıya proc. coracoideus adi verilir (17).

Humerus, bir adet primer, değișik sayıda sekonder olmak üzere iki ossifikasyon merkezi (OM)'nden kemikleşir. Distal epifizin kapanması 6 ayda tamamlanır. Proksimal epifiz ise 15-18 ayda kapanmaktadır $(1,22)$.

Radius üç OM'den kemikleşir. Bunlardan biri diyafize, ikisi ise proksimal ve distal epifize ait merkezlerdir. Proksimal epifiz 6. ayda kapanmaktadır. Distal epifizdeki kapanma 15 ayda şekillenir $(1,11)$.

Ulna da uiç OM'ye sahiptir. Bunlardan biri corpus, diğer ikisi ise olecranon ve proc. styloideus üzerindedir (5).

Ossa carpi doğumda tamamen kıkırdak yapıdadır. Postnatal ikinci hafta sonrasında kemikleşmeye başlar. Fakat os carpi accessorium, os carpale I ve II daha geç kemikleşmeye başlar. Tavşanda metakarpal diyafiz doğumdan 8-12 gün sonra tamamen kemikleşir. Bu kemiklerin uzaması, her bir metacarpus'un distal'inde yer alan tek epifiz plağından sağlanır. Bu kemiklerde proksimal epifiz yoktur. Her phalanx bir adet PM ve bir adet SM'den gelişir. 'Phalanx distalis'in kemikleşmesi doğumdan önce tamamlanır. Tavşanın susam kemikleri doğumda kıkırdaktır. Postnatal hayatın 1. ayında büyük susam kemikleri, 5. yılında ise küçük susam kemiklerinde kemikleşme şekillenir (1).

Yeni Zelanda tavşanları üzerinde yapılan bu çalışmada, ön ekstremite kemiklerinin, doğumdan 198. güne kadar olan büyüme ve gelişimleri incelenerek dönemsel iskelet yapısı hakkındaki bilgi ihtiyacının bir ölçïde karşılanması amaçlanmaktadır. Bunun yanında, PM ve SM'lerin yerleri ve sayıları belirlenmeye çalışılarak, ön ekstremite kemiklerinin ayrı ayrı epifiz plaklarının kapanma zamanları tespit edilmiştir.

\section{Materyal ve Metot}

Osteolojik gelişimin ön ekstremitelerde zamana bağlı modellerinin belirlenmesi amacıyla materyal olarak $(0,7,21,42,70,105,147,168,196$ günlük) doku farklı çağda 8 'er, toplam 72 adet sağlıklı erkek Yeni Zelanda tavşanı kullanılmıştır.

Kullanilan yem; \%16 ham protein (en az), \%10 ham selülöz (en çok), \%10 ham kül (en çok), kalsiyun \%0.81.4 (en az-en çok), fosfor $\% 0.6$ (en az), sodyum $\% 0.3-0.4$ (en az-en çok), $5000 \mathrm{IÜ} / \mathrm{Kg}$ A vitamini, $1000 \mathrm{IÜ} / \mathrm{Kg}$ D3 vitamini ve en az $30 \mathrm{Mg} / \mathrm{Kg}$ E vitamini içermektedir.

Kadavralarnn ön ekstremite kemikleri, diseke edilerek ortaya çıkarılmıştır. Makroskobik olarak okulometre, dijital kumpas ve çıplak gözle alınadak bulguların da kaydedilmesinin ardından double staining (alizarin red-S ve alcian blue) yöntemi kullanılarak epifiz kıkırdakları (mavi), büyüme plakları ve kemikleşme odakları (şarap rengi) görülebilir bir duruma getirilmiştir.

Diseksiyondan sonra çiftler halinde saklama kaplarında tutulan bacaklar double staining tekniğ ile boyanmıştır $(3,8)$. Literatüre uygun olarak "A"|çözeltisi (300 mg alcian blue, $100 \mathrm{ml} \% 70$ 'lik etanol içermektedir) ve "B" çözeltisi (100 mg alizarin red-S, $100 \mathrm{ml} \% 95$ 'lik etanol içermektedir) oluşturulmuş ve sonra bu çözeltiler birbirine karıştırılıp $100 \mathrm{ml}$ glasial asetik asit ile $1700 \mathrm{ml}$ \%70'lik etanol eklenerek boyama solusyonu hazırlanmıştır. Hazırlanan boyama solusyonu içerisinde $40^{\circ} \mathrm{C}$ 'de dört gün boyunca bekletilen ön bacaklar iki saat süreyle akan su altında yıkanmıştır. Yıkamanın ardından, ön ekstremiteler üç gün kadar \%2'lik potasyum hidroksit $(\mathrm{KOH})$ ile muamele edilmiş, daha sonra çevie dokular temiz bir görünüme ulaşıncaya kadar $\% 20$ gliserin içeren $\% 1$ 'lik $\mathrm{KOH}$ solusyonu içerisinde bekletilmiştir. Materyaller surasiyla $\%, 50$ ve \%80'lik gliserin'e konularak her birinde yedi gün bırakılmış, daha sonra \% 100'lük gliserin içerisine alinarak saklanmıştır.

\section{Bulgular}

Yeni Zelanda tavşanı'nda ön ekstremite kemiklerinde gelişim, birer adet PM ve farklı sayıda SM'de kemikleşme şeklinde gözlenmiştir. Birinci grup materyallerde ossa carpi ve os coracoides haricindeki tüm ön ekstremite kemiklerinde PM kemikleşmesinin başlamış olduğu görülmüştuir.

Boyamalara örnek olarak üç haftalık Yéni Zelanda tavşanı'nda alizarin red-S ve alcian blue ile boyanmış sağ ön ekstremitenin lateral'den görünüşü verilmişstir (Şekil 1). 


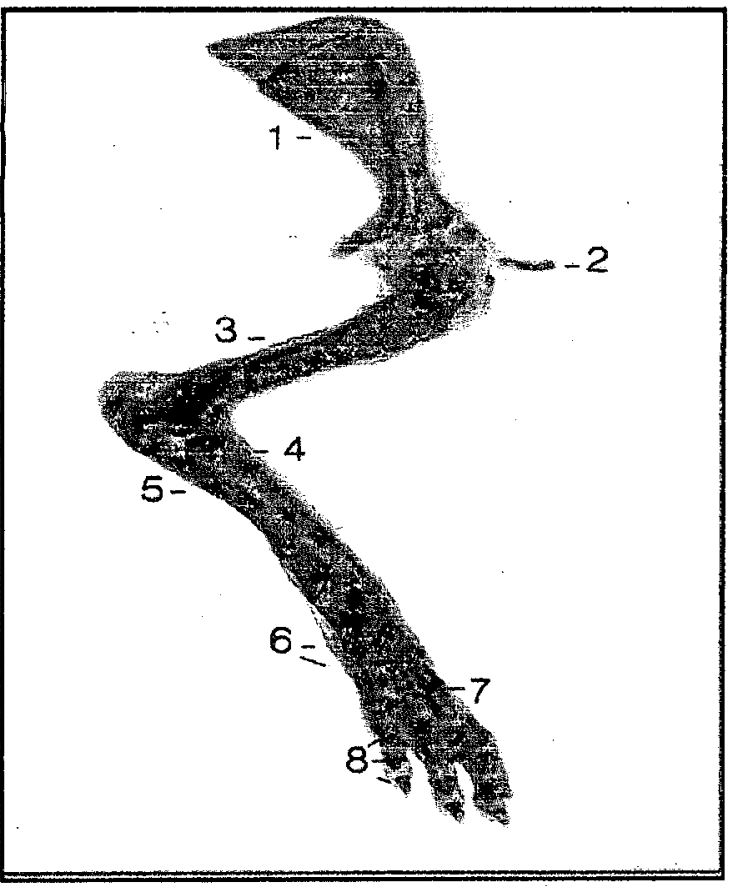

Şekil 1. Üç haftalık Yeni Zelanda tavşanı sağ ön ekstremitesi (lateral'den görünuiş). Alizarin red-S ve alcian blue. x2. 1 Scapula, 2 Clavicula, 3 Humerus, 4 Radius, 5 Ulna, 6 Ossa carpi, 7 Ossa metacarpalia, 8 Ossa digitorum manus.

Figure 1. The right thoracic limb of the New Zealand rabbit aged three weeks (lateral view). Alizarin red-S and alcian blue. x2. 1 Scapula, 2 Clavicula, 3 Humerus, 4 Radius, 5 Ulna, 6 Ossa carpi, 7 Ossa metacarpalia, 8 Ossa digitorum manus.

Scapula'da biri PM, dördü SM olmak üzere toplam 5 adet OM'nin geliştiği görülmüştür. Yeni doğmuş tavşanlarda ortalama $6.39 \mathrm{~mm}$ genişliğe, $8.98 \mathrm{~mm}$ uzunluğa ve $0.94 \mathrm{~mm}$ kalınlığa sahip olan scapula'nın, postnatal 198. günde $38.72 \mathrm{~mm}$ genişliğe, $71.64 \mathrm{~mm}$ uzunluğa ve $3.01 \mathrm{~mm}$ kalınlığa ulaştı̆̆ belirlenmiştir.
Clavicula'nun bir adet PM ve bir adet SM'ye sahip olduğu gözlenmiştir. Clavicula'nın kemikleşmiş kısmının postnatal ilk günde ortalama $5.30 \mathrm{~mm}, 198$. günde ise $22.50 \mathrm{~mm}$ uzunlukta olduğu belirlenmiştir. Clavicula'nın genişliği ise ilk gün $0.30 \mathrm{~mm}$ iken yirmi sekizinci haftada $1.90 \mathrm{~mm}$ olarak ölçülmüştür.

Os coracoides, altınc grupta processus coracoideus'un gelişim kıkırdağı içerisinde oval bir SM olarak ortaya çıkmiştır. Ilk grubun processus coracoideus'u anlamlı bir ölçüm yapılamayacak kadar küçük kıkırdak bir yapı olarak gözlenmiştir. Altıncı grup materyallerde ilk kez kemikleşmeye başlayan SM $0.53 \mathrm{~mm}$ mediolateral, 0.93 mm proximodistal çapa sahiptir. 198. günde processus coracoideus'un mediolateral boyu $5.74 \mathrm{~mm}$, proximodistal eni $3.42 \mathrm{~mm}$ ve craniocaudal kalınlığ $1.75 \mathrm{~mm}$ olarak be lirlenmiştir.

Humerus'un bir PM, iki SM proksimal epifizde, iki PM distal epifizde olmak üzere toplam beş OM'nden kemikleştiği görülmuiştür. Birinci grupta humerus'un eni ortalama $1.59 \mathrm{~mm}$, boyu ise $10.65 \mathrm{~mm}$ iken, dokuzuncu grupta eni $6.31 \mathrm{~mm}$ boyu da $70.79 \mathrm{~mm}$ olarak tespit edilmiştir.

Radius'un ve ulna'nın diyafizleri dışında birer proksimal birer distal SM'ye sahip oldukları saptanmıştır. Radius'un yeni doğmuş materyalde ortalama uzunluğunun $9.03 \mathrm{~mm}$, genişliğinin $0.84 \mathrm{~mm}$ olduğu belirlenmiştir. 198. günde radius ortalama $67.34 \mathrm{~mm}$ boya, $4.80 \mathrm{~mm}$ ene ulaşmıştır. Ulna'nın eni postnatal birinci günde $0.93 \mathrm{~mm}$ iken 198. günde $6.57 \mathrm{~mm}$ olàrak ölçuilmüştür. Boyu ise ilk grupta $10.48 \mathrm{~mm}$ olarak belirlenirken dokuzuncu grupta $80.78 \mathrm{~mm}$ olarak tespit edilmiştir.

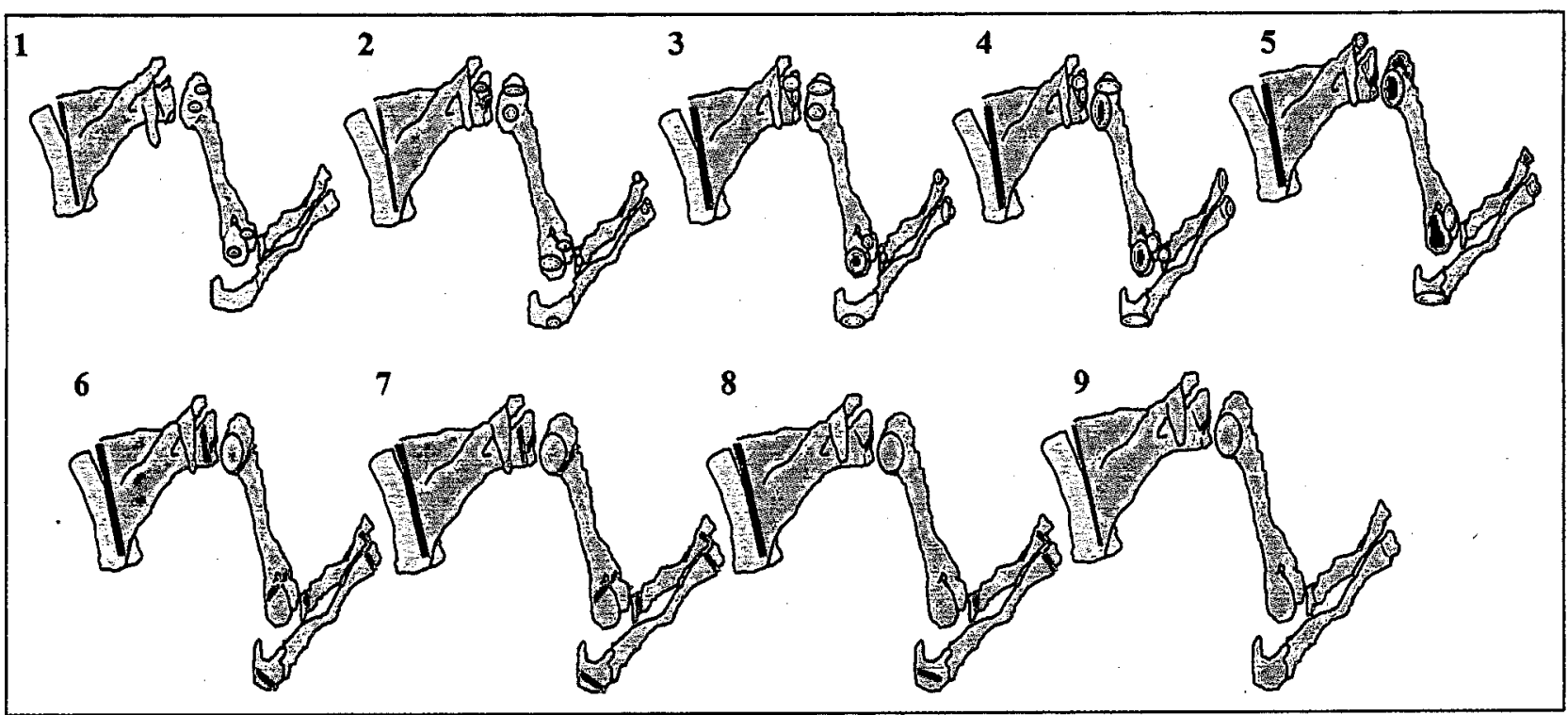

Şekil 2. Dokuz gruptaki scapula, humerus ve antebrachium'un gelişimlerinin şematik görünümü. Mavi renk: kıkırdak kısımlar, Pembe renk: kemikleşmiş bölgeler, Kırmızı renkli odaklar: sekonder kemikleşme merkezleri, Kırmızı renkli çizgiler: epifiz plakları. Figure 2. Schematic view of the developing scapula, humerus and antebrachium in nine groups. Blue color: Cartilaginous portions, Pink color: Ossified area, Points with red color: Secondary ossification centers, Lines with red color: Epiphysis plates. 


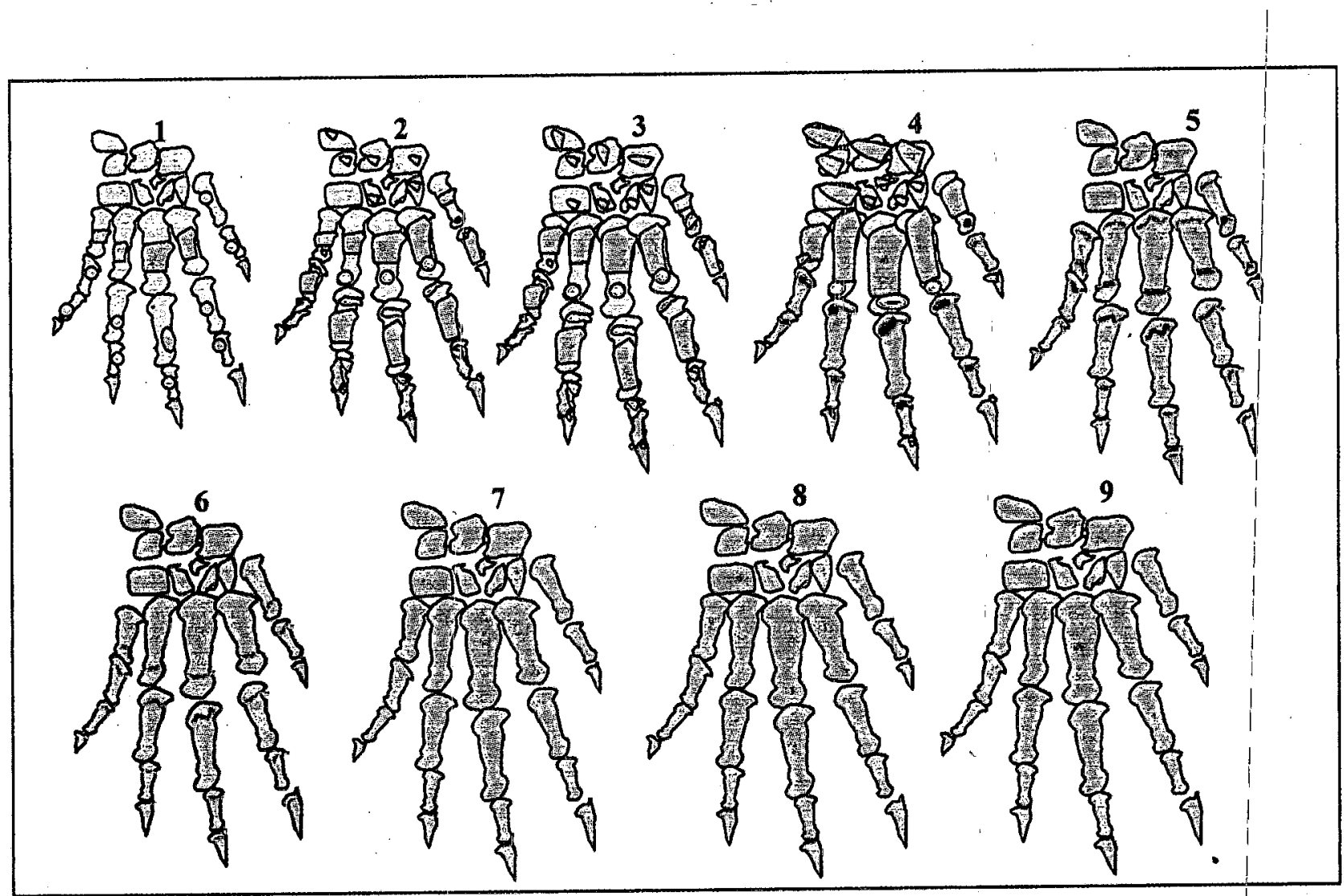

Şekil 3. Skeleton manus'un gelişiminin şęmatik görünümü (dokuz grupta). Mavi renk: kıkırdak kısımlar, Pembe renk: kemịikleşmiş kısımlar, Kırmızı renkli odaklar: sekonder kemikleşme merkezleri, Kırmızı renkli çizgiler: epifiz plakları.

Figure 3. Schematic view of the developing skeleton manus (in nine groups). Blue color: Cartilaginous portions, Pink color: Ossified area, Points with red color: Secondary ossification centers, Lines with red color: Epiphysis plates.

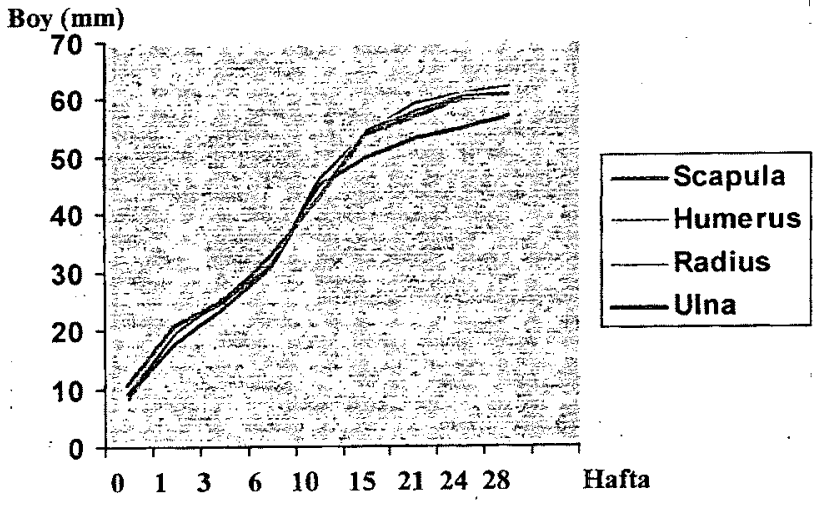

Şekil 4. Yeni Zelanda tavşanı'nda ön extremiteye ait dört kemiğin gelişim grafĭgi ( $\mathrm{mm} / \mathrm{hafta}$ ).

Figure 4. A linear graphic about the developing four bones of thoracic limb in the New Zealand rabbit ( $\mathrm{mm} /$ week).

Birinci gruptaki tavşanların bileğinde herhangi bir kemikleşme odağ (PM ve SM) görülmemiştir. Ikinci grubun bilek kemiklerinden proksimal sıradaki dört kıkırdak taslakta ve distal sıradaki taslakların ikisinde (os carpale I ve os carpale IV) kemikleşme görülmüştür. Üçüncü grupta bilek kemiklerine ait kıkırdak taslaklarm sekiz tanesinde kemikleşme odaklarının varlığ saptanmıştır. Bu gruptaki tavşanlarda os carpi centrale'ye ait herhangi bir kemikleşme merkezi gözlenememiştir. Dördüncü grup materyal'de os carpi centrale'nin de kemikleşmeye baş-

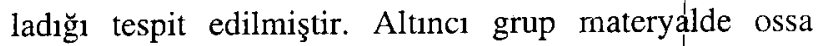
carpi'de kemikleşmenin gelişimini tamamladığ 1 ve sadece eklem yüzlerinde ince bir kıkırdak dokunun yer aldığı görülmüştür. Yedinci, -sekizinci ve dokuzuncu gruplarda ossa carpi'de büyümenin sürdüğü belirlenmiştir.

Ossa metacarpalia'nın distal gelişim kıkırdakları içerisindeki SM'ler bir haftalı materyalde kemikleşmeye başlamıştır. On haftalık tavşanlara ait metacarpus'larda proksimal uçların bütünüyle kemikleştiği gölüulmüş̧ür. 21,22 ve 23. haftalarda metacarpus'larn epifizleri gözlenemezken, büyümenin devam ettiği tespit edilmiştir.

Phalanx'lanın da PM'sinde doğumda kemikleşmenin başlamış olduğu göruilmüşsür. Ikinci grup tavşanların phalanx'larında, phalanx distalis'ler hariç, proksimial gelişim kıkırdaklarının içerisinde kemikleşmeye başlamış birer nokta dikkati çekmektedir. Bunlar proksimalde yer alan SM'lerdir. Altunc1 grup materyallerde phalanx'ların bütünüyle kemikleştiği görülmüştür.

Ön ekstremitede üçüncü haftadan sónraki dönemlerde articulatio metacarpophalangea ve articulatio interphalangea'nn plantar'inda yer alan susam kemiklerinde ossifikasyon' un başladığı ve bu kemiklerin belirgin hale geldiği görülmüştür. Susam kemiklerinin altuncı haftada $1 \mathrm{~mm}$ ile $1.9 \mathrm{~mm}$ arasında çapa sahip olduğu, 24. haftada ise $2.3 \mathrm{~mm}$ ile $4 \mathrm{~mm}$ büyüklüğge ulaştığı belirlenmiştir. 
Tablo 1. Dokuz grupta sağ ve sol ön ekstremite kemiklerinin en, boy ve kalınlıklan. Çizelgede verilen rakamların herbiri 8 ( $n=8$ ) adet materyalden alınan ölçümlerin ortalama değerleridir. SE<0.09. SC scapula, CL clavicula, HU humerus, RA radius, UL ulna, MCII os metacarpale II, PHD phalanx distalis.

Table 1. The width, height and thickness of the right and left thoracic limb bones in nine groups.

SC scapula, CL clavicula, HU humerus, RA radius, UL ulna, MCII os metacarpale II, PHD phalanx distalis.

\begin{tabular}{|c|c|c|c|c|c|c|c|c|c|c|c|}
\hline & $\because \cdot$ & Grup: & 1 & 2 & 3 & 4 & 5 & 6 & 7 & 8 & 9 \\
\hline \multirow[t]{6}{*}{ SC } & \multirow[t]{2}{*}{ En } & Sağ & 6.39 & 10.93 & 11.47 & 18.75 & 23.40 & 34.59 & 38.60 & 38.94 & 38.72 \\
\hline & & Sol & 6.28 & 10.58 & 11.28 & 18.10 & 22.19 & 33.15 & 37.66 & 37.63 & 37.86 \\
\hline & \multirow[t]{2}{*}{ Boy } & Săg & 8.98 & 17.07 & 21.75 & 32.19 & 44.76 & 63.96 & 67.26 & 69.43 & 71.64 \\
\hline & & Sol & 8.84 & 16.94 & 21.48 & 31.61 & 41.37 & 60.91 & 66.73 & 68.47 & 71.25 \\
\hline & \multirow[t]{2}{*}{ Kalınlık } & Sağ & 0.94 & 1.12 & 1.32 & 1.96 & 2.39 & 2.74 & 2.91 & 2.98 & 3.01 \\
\hline & & Sol & .0 .74 & 0.99 & 1.24 & 1.89 & 2.26 & 2.60 & 2.68 & 2.93 & 2.95 \\
\hline \multirow[t]{4}{*}{$\mathrm{CL}$} & \multirow[t]{2}{*}{ En } & Săg & 0.30 & 0.71 & 0.85 & 1.05 & 1.12 & 1.44 & 1.70 & 1.81 & 1.90 \\
\hline & & Sol & 0.27 & 0.68 & 0.80 & 1.04 & 1.08 & 1.40 & 1.65 & 1.73 & 1.88 \\
\hline & \multirow[t]{2}{*}{ Boy } & Sağ & 5.30 & 8.23 & 9.17 & 15.49 & 17.56 & 18.62 & 19.59 & 21.85 & 22.50 \\
\hline & & Sol & 5.26 & 8.20 & 9.15 & 15.44 & 17.50 & 18.52 & 19.50 & 21.71 & .22 .46 \\
\hline \multirow[t]{4}{*}{$\mathrm{HU}$} & \multirow[t]{2}{*}{ En } & $\mathrm{Sağ}$ & 1.59 & 2.41 & 2.78 & 3.79 & 4.56 & 5.38 & 5.40 & 6.29 & 6.31 \\
\hline & & Sol & 1.42 & 2.27 & 2.62 & 3.50 & 4.41 & 5.03 & 5.25 & 6.09 & 6.10 \\
\hline & \multirow[t]{2}{*}{ Boy } & Sağ & 10.65 & 19.17 & 24.38 & 35.02 & 47.68 & $\epsilon^{0} .60$ & 67.34 & 69.67 & 70.79 \\
\hline & & Sol & 10.38 & 17.09 & 23.94 & 34.77 & 45.07 & 59.45 & 66.52 & 68.93 & 70.35 \\
\hline \multirow[t]{4}{*}{ RA } & \multirow[t]{2}{*}{ En } & Să̆ & 0.84 & 1.55 & 1.97 & 3.01 & 3.60 & 4.48 & 4.76 & 4.46 & 4.80 \\
\hline & & Sol & 0.72 & 1.31 & 1.84 & 2.74 & 3.42 & 4.24 & 4.62 & 4.47 & 4.66 \\
\hline & \multirow[t]{2}{*}{ Boy } & Săg & 9.03 & 16.94 & 22.32 & 32.87 & 45.21 & 64.39 & 66.14 & 66.28 & 67.34 \\
\hline & & Sol & 8.86 & 15.85 & 21.39 & 32.43 & 43.29 & 62.65 & 65.43 & 65.66 & 66.30 \\
\hline \multirow[t]{4}{*}{ UL } & \multirow[t]{2}{*}{ En } & Săg & 0.93 & 1.80 & 2.71 & 3.68 & 4.19 & 5.24 & 5.96 & 6.59 & 6.57 \\
\hline & & Sol & 0.90 & 1.60 & 2.46 & 3.73 & 3.89 & 5.16 & 5.61 & 6.37 & 6.36 \\
\hline & \multirow[t]{2}{*}{ Boy } & $\mathrm{Sag}$ & 10.48 & 20.69 & 25.72 & 40.04 & 56.19 & $75.83^{\circ}$ & 78.13 & 79.81 & 80.78 \\
\hline & & Sol & 10.29 & 19.36 & 25.64 & 37.91 & 51.17 & 72.54 & 76.35 & 79.14 & 80.29 \\
\hline \multirow[t]{4}{*}{ MCII } & \multirow[t]{2}{*}{ En } & $\mathrm{Sağ}$ & 1.10 & 1.20 & 1.60 & 1.90 & 2.35 & 2.53 & 2.80 & 2.98 & 3.12 \\
\hline & & Sol & 1.08 & 1.16 & 1.53 & 1.85 & 2.27 & 2.49 & 2.72 & 2.90 & 3.09 \\
\hline & \multirow[t]{2}{*}{ Boy } & $\mathrm{Sağ}$ & 1.60 & 5.30 & 6.40 & 7.05 & 15.12 & 17.49 & 17.53 & 19.38 & 20.50 \\
\hline & & Sol & 1.58 & 1.27 & 6.35 & 7.00 & 15.07 & 17.40 & 17.46 & 19.31 & 20.44 \\
\hline \multirow[t]{4}{*}{ PHD } & \multirow[t]{2}{*}{ En } & Sağ & 0.52 & 0.61 & 0.84 & 1.27 & 1.96 & 2.06 & 2.49 & 2.56 & 2.76 \\
\hline & & Sol & 0.50 & 0.59 & 0.83 & 1.25 & 1.91 & 2.00 & 2.46 & -2.55 & 2.76 \\
\hline & \multirow[t]{2}{*}{ Boy } & Sağ & 0.90 & 1.75 & 1.90 & 4.39 & 5.73 & 6.18 & 6.43 & 7.96 & 8.29 \\
\hline & & Sol & 0.88 & 0.70 & 1.84 & 4.34 & 5.72 & $6.11^{\circ}$ & 6.40 & 7.93 & 8.10 \\
\hline
\end{tabular}

Birinci (0 günlük)-dokuzuncu (28. haftalık) gruba ait scapula, humerus ve antebrachium'un (Şekil 2) ve skeleton manus'un (Şekil 3) gelişimi şematize edilmiştir. Şekil 4 ve Tablo 1'de rakamsal bulgular verilmiştir.

\section{Tartışma ve Sonuç}

Memeli hayvanlarda scapula'nın kemikleşmesinin bir adet PM ve iki ya da üç adet SM tarafından sağlandı $\breve{g}$, insanda ise scapula'nın 8 adet SM'den kemikleştiği belirtilmektedir (1). Scapula equidae'de dört, ruminantia'da üç merkezden kemikleşmektedir (11). Farelerde scapula'nın bir PM ve bir SM'den kemikleştiği bildirilmiş̧ir (21). Köpeklerde scapula'nın corpus scapulae ve tuber scapulae'da bulunan toplam iki adet OM'ye sahip olduğu belirtilmektedir $(4,12)$. Yeni Zelanda tavşanı'nda yapılan bu çalışmada scapula'nın literatüre $(1,11)$ benzer şekilde bir primer, üç SM'den geliştiği görülmüştür. Ayrıca, bu dört OM dışında scapula üzerinde proc. coracoideus'a ait bir merkezin daha bulunduğu gözlenmiştir.

Hayvanlar üzerinde yapılmış osteolojik gelişim çalışmalarında $(4,15,20,21,24)$ clavicula'nın gelişiminden söz edilmemiştir. Insanda corpus clavicula'nun dışında extremitas sternalis clavicula'da bir OM'nin varlığına değinilmiştir (22). Yeni Zelanda tavşanı'nda yapılan çalışmada da clavicula'nın bir adet PM'ye, bir adet SM'ye sahip olduğu gözlenmiştir. Sözii edilen SM'nin insanda clavicula'nın craniomedial ucunda bulunduğu bildirilmesine (22) rağmen Yeni Zelanda tavşanlarında clavicula'nın caudolateral ucunda bulunduğu saptanmıştır.

Koyun ve keçilerde proc. coracoideus'un 5-6. aylar arasında ilk kez kemikleşmeye başladı̆̆ı, 11. ayda ise burada kemikleşmenin sona erdiği bildirilmiştir (23). Ankara keçisinde proc. coracoideus'a ait epifiz plağının 18. 24. aylar arasında kapandığı belirtilmiştir (20). Yeni Zelanda tavşanı'nda proc. coracoideus'un gelişiminin 15 
haftalık materyallerde oval bir SM şeklinde başladığı, 2428. haftalar arasında ise corpus ile kaynaşarak kemikleşmesini tamamladığı gözlenmiştir.

Yeni Zelanda tavşanı'nda humerus'un, köpeklerde, Ankara keçisinde, equidae'de ve memeli hayvanlarda $(1,4,11,12,20)$ bildirilenlere uygun olarak, biri primer dördü sekonder, toplam beş OM'den kemikleştiği görülmïiştïr.

Tavşanda humerus'un, distal epifizindeki kapanmanın 6 ayda, proksimal epifizinde ise 15 - 18 ayda tamamlandığı belirtilmiştir (1). Yapılan çalışmada humerus'ta distal epifizin literatür'e uygun olarak 6. ayda kapandığı, fakat proksimal epifizin literatür'de belirtilenden çok önce, 7. ayda kapandığı tespit edilmiştir.

Radius'un proksimal ve distal epifizden ya da üç OM'den kemikleştiği belirtilmiştir $(4,11,12,20)$. Radius'ta proksimal epifizin diyafiz ile kaynaşmasının, distal epifizden her zaman çok daha erken olduğu söylenmektedir. Tavşanın proksimal epifizinin 6. ayda kapandığ 1 , distal epifizdeki kapanmanın ise 15 ayda tamamlandığı bildirilmiştir (1). Köpeklerde $(4,12)$ SM'lerin postnatal 10-25. günlerde kemikleşmeye başladığı belirtilmiştir. Bildirilenlere uygun olarak Yeni Zelanda tavşanı'nda da radius'un, diyafizinin dışında bir proksimal bir distal SM'ye sahip olduğu saptanmıştır. Bir haftalık tavşanların radius'larında SM'lerin varlığı belirlenmiştir. 15-21. haftalarda radius'ların SM'leri her iki uçta da corpus ile kaynaşmıştır. Altıncı ve yedinci aylarda ise materyallerin radius'larında epifiz plaklarının bütünüyle kemikleşmiş olduğu gözlenmiştir.

Ulna'nın memeli hayvanlarda, üç OM'ye sahip olduğu ve bunlardan birinin corpus, diğer ikisinin ise olec ranon ve proc. styloideus üzerinde bulunduğu belirtilmiştir (5). Bir PM ve iki SM'nin varlığ bildirilmiştir $(1,4,11,12,20)$. Bu iki SM'nin, köpeklerde 40-45. günlerde kemikleşmeye başladı̆̆ 1 , Ankara keçisinde 48 - 54 ayda, equidae'de proksimal epifizin 18 ayda, distal epifizin ise 42 ayda kapandığı söylenmektedir $(4,11,12,20)$. Belirtilen bir PM ve iki SM'nin varlığı, yapılan çalışmada tavşan ulna'larında da gözlenmiştir. 5-6 aylık materyallerin ulna'larında SM'lerin her iki uçta da corpus ile kaynaştığı. 7 aylık materyal'de ise epifiz plaklarının kapandı ğ

Ossa carpi'ye ait OM'lerin endochondral olarak ve sadece doğumdan sonra geliştiği bildirilmiştir. Tavşanda ossa carpi'nin doğumda tamamen kıkırdak yapıda olduğu ve postnatal ikinci hafta sonrasında kemikleşmeye başladığı belirtilmektedir. Fakat os carpi accessorium, os carpale I ve II'in daha geç kemikleşmeye başladığı bildirilmektedir (1). Siyam kedisinde ossa carpi'nin yeni doğanlarda kemikleşmiş olmadığı belirtilmiştir (16̆). Köpeklerde ossa carpi'nin postnatal 18-45. günler arasında ilk kez kemikleşmeye başladığı bildirilmiştir $(4,12)$. Yeni Zelanda tavşanı'nda da doğumdan sonraki ilk gün ossa carpi'nin tamamen kıkirdak yapıda olduğu göruilimüştür. Bir haftalık tavşanlarda ossa carpi'nin proksimal s1rasındaki dört kıkırdak taslakta ve distal sıradaki taslakların ikisinde (os carpale I ve IV) kemikleşme görülmüştür. Altı haftalık materyallerde ossa cárpi'nin hepsinde kemikleşmenin başladığı tespit edilmiştir. Yedi aylık tavşanlara ait ossa carpi' de büyümenin sürdiuğü belirlenmiştir.

Tavşanda metakarpal diyafizin doğumdan $8-12$ gün sonra tamamen kemikleștiği söylenmektedir (1). Aynı kaynakta bu kemiklerin uzamasının, distal'de yer alan tek epifiz plağından sağlandığı ve bu kemiklerde proksimal epifizin bulunmadığı bildirilmiştir. Köpeklerde metacarpus I-V'in, equidae'de metacarpus III'ün ptoksimal ve distal epifize sahip olduğu belirtilmiştir $(4,11)$ Insanda ossa metacarpalia bir diyafiz ve bir distal epifize sahiptir (22). Metacarpus I'in ise diğerlerinden farklı olarak diyafiz dışında proksimal bir OM'si vardır. Yeni Zelanda tavşanı'nda postnatal birinci gün metacarpus I-V'in PM'lerinin kemikleşmeye başlamış olduğu gözlenmiştir. Bir haftalık materyalde SM'leri kemikleşmeye başlamıştır. Yapılan çalışmada Yeni Zelanda tavşanı'nın metacarpus'larında literatüre $(4,11,20)$ uygun olarak proksimal epifizin de var olduğu belirlenmiştir.

Literatüre göre tavşanda her phalanx bir adet PM ve bir adet SM'den gelişir (1). SM'nin proksimal epifizde meydana geldiği ve distal epifiz plağının bulunmadığı belirtilmiştir $(4,11,12,16)$. Baş parmağın phallanx proximalis'inin epifizden yoksun olduğu ve phalanx distalis'in bütün hayvan türlerinde tek bir OM'den geliştiği bildirilmiştir (1). Phalanx'lann hem proksimal hem de distal epifize sahip olduğu da bildirilmektedir $(20,23)$. Literatüre $(1,4,10,12,16)$ benzer şekilde, Yeni Zelanda tavşanı'nda da yalnız proksimal epifizin bulưnduğu ve SM'nin burada şekillendiği görïlmmüştür. Yeni doğan tavşan yavrularında phalanx distalis'lerin kemikleşmiş olduğu gözlenmiştir. Phalanx proximalis'in ve phalanx media'nın kemikleşmeye başladığ1 saptanmıştır. Tavşanda phalanx distalis'lerde proksimal SM'nin varlı̆̆ tespit edilememiştir.

Tavşanda articulatio metacarpophalangeae'nın ve articulatio interphalangeae'nın palmar'ında birkaç susam kemiği bulunduğu bildirilmiştir (17). Tavşanın susam kemikleri doğumda kıkırdaktır ve postnatal hayatın 1 . ayında büyük susam kemikleri, 5. yılında ise küçük susam kemiklerinde ossifikasyon şekillenir (1). Ça- 
lişmada Yeni Zelanda tavşanı'nda articulatio metacarpo phalangeae'da iki ve articulatio interphalangea'da ise bir adet susam kemiği bulunduğu saptanmıştır. Ossa sesamoideae'da postnatal üçüncü haftadan sonraki dönemlerde kemikleşmeler görülmüştür.

Tavşanda ilk 12 haftalık dönem içerisinde erişkin kemik yapısının şekillendiği belirtilmekte, büyümenin ise 17-33. haftalar arasında sona erdiğini bildirilmektedir (13). Kemik gelişimi ve epifizeal büyüme, tavşanlar 6 aylik olduklarında sona ermekte ve epifiz plakları kapanmaktadır (14). Tavşanda büyüme hızının postnatal ilk 28-42. günlere kadar çok yüksek olduğu ve giderek azaldığı belirtilmektedir (24). Yapılan çalışmada hızlı büyüme sürecinin postnatal 15. haftaya kadar devam ettiği saptanmıştır. Yirmi birinci haftadan sonra büyüme yavaşlamış, altı aylık materyallerle sonraki grup arasında önem taşımayacak kadar küçük bir değişim belirlenmiştir.

Literatür'de tavşan'a ait sağ ve sol bacak kemikleri arasinda kayda değer bir büyüme farklılığına rastlanmadığı belirtilmiştir $(15,25,28)$. Tavşanlarda yapılan bu çalışmaları doğrular nitelikte, Yeni Zelanda tavşan'n'nı ön ekstremite kemiklerinin gelişimlerinde OM, ilk kemikleşme zamanları ve epifiz plaklarının kapanmasında sağ bacak ile sol bacak arasında herhangi bir farklılık görülmemiştir. Ancak, büyüklükleri bakımından sağ ve sol bacaklara ait materyallerin tümü arasında istatistiksel olarak $(\mathrm{p}<0,09)$ anlamlı bir farklılık göze çarpmıştır. Yeni Zelanda tavşan'lanında sağ ön bacağa ait kemiklerin büyüklüklerinin soldakilerin büyüklüklerinden fazla olduğu saptanmıştır.

Sonuç olarak, Yeni Zelanda tavşanında ön ekstremite kemiklerinin, doğumdan 198. güne kadar olan gelişimleri incelenmiş ve büyüklükleri ölçülmüştür. Ön ekstremite kemiklerinde ossifikasyon'un doğumdan önce başladığ 1 , kemik gelişim hızının ilk 15 haftada yüksek olduğu ve 28. haftaya kadar giderek azaldığı saptanmıştır. Yapılan çalışmanın 28 haftalık son periyoduna ait ön ekstremite kemiklerinde büyüme ve gelişimin durduğu gözlenmiştir:

\section{Kaynaklar}

1. Barone R (1986): Anatomie Comparee Des Mammiferes Domestiques. Osteologie. Vigot Freres Paris.

2. Brown RA, Blunn GW, SalIsbury JR, Byers PD (1993): Two patterns of calcification in primary (physeal) and secondary (epiphyseal) growth cartilage. Clin Orthop Res, 294, 318-324.

3. Cerveny C (1972): Differentiation staining of bone tissue on topographic anatomic sections with alizarin red. Acta Vet Brno, 41, 303-307.
4. Chapman WL (1965): Appearance of ossification centers and epiphysial closures as determined by radiographic techniques. JAVMA, 147, 138-141.

5. Doğuer S, Erençin Z (1962): Evcil Hayvanların Komparativ Osteolojisi. Ankara Üniversitesi Basımevi, Ankara.

6. Dursun N (2000): Veteriner Anatomi 1. Medisan Yayınevi, Ankara.

7. Dyce KM, Sack WD, Wensing CJG (1987): Textbook of Veterinary Anatomy. WB Saunders Company, London.

8. Erdoğan D, Kadıoğlu D, Peker T (1995): Visualisation of the fetal skeletal system by double staining with alizarin red and alcian blue. Gazi Med J, 6, 55-58.

9. Erençin Z, Sağlam M (1969): Genel Histoloji. Ankara Üniversitesi Basımevi, Ankara.

10. Gatzi V (1969): Ossifikation der extramitaten des kaninchens (Oryctolagus cuniculus). Rev Suis Zool, 76, 383 386.

11. Getty R (1975): The Anatomy of the Domestic Animals. WB Saunders Company, London.

12. Hare WCD (1961): The ages at which the centers of ossification appear roentgenographically in the limb bones of the dog. Amer J Vet Res, 90, 825-835.

13. Hörner K, Drescher B (1992): The age dependent development of the long bones diaphyses by New Zealand rabbits and chinchilla-bastard-experimental-rabbits. Anat Histol Embryol, 21, 175-186.

14. Jowsey J (1968): Age and species differences in bone. Cornell Vet, 58, 74-94.

15. Lerner AL, Kuhn JL (1997): Characterization of regional and age-related variations in the growth of the rabbit distal femur. J Orthop Res, 15, 353-361.

16. Lopez MIV, Auton JMV, Moreno F, Latorre R, Zarzosa GR (1993): Chronology of the postnatal ossification of the thoracic autopodo in Siam cat (Felis catus L.). Anat Histol Embryol, 22, 39-47.

17. Mclaughlin CA, Chiasson RB (1990): Laboratory Anatomy of the Rabbit. McGraw-Hill Companies, Toronto.

18. Miller EM (1965): Anatomy of the Dog. WB Saunders Company, London.

19. Nickel R, Schummer A, Seiferle E (1986): The Anatomy of the Domestic Animals. Verlag Paul Parey, Hamburg.

20. Olgun M (1978): Ankara Keçisi Iskelet Kemiklerinde Postnatal Kemiklerin Anatomik Yönden Araşttrlması. Doktora tezi. Ankara Üniversitesi Sağlk Bilimleri Enstituisü.

21. Patton JT, Kaufman MH (1995): The timing of ossification of the limb bones, and growth rates of various long bones of the fore and hind limbs of the prenatal and early postnatal laboratory mouse. J Anat, 186, 175-185.

22. Platzer W (1986): Anatomi Atlasl. Kemik ve Kaslar. Sermet Matbaası, Krri:lareli.

23. Rajtova V (1974): Postnatal development of the bones of the limbs in sheep and goat. Anat Histol Embryol, 3, 29-39.

24. Rao DR, Sunki GR, Johnson WM, Chen CP (1977): Postnatal growth of New Zealand white rabbit (Oryctolagus cuniculus). J Animal Sci, 44, 1021-1025.

25. Rudicel S, Kendrick E, Peiker RR (1985): Dimension of the rabbit femur during growth. Amer J Vet Res, 46, 268269. 
26. Sickle DCV (1965): A comparative study of the postnatal elbow development of the greyhound and German shepherd dog. JAVMA, 147, 1650-1651.

27. Van De Graaff KM (1998): Human Anatomy. The McGraw-Hill Companies, Boston.

28. White AA, Panjabi MM, Hardy RJ (1974): Analysis of mechanical symmetry in rabbit long bones. Acta Orthop Scand, 45, 328-336.
Gelis tarihi: 14.10.2002 / Kabul tarihi: 12.11.2002

Yazışma adresi:

Dr. Ayhan Düzler

Erciyes Üniversitesi, Veteriner Fakültesi,

Anatomi Anabilim Dall

Kayseri 